\title{
КЛИНИЧЕСКАЯ ХАРАКТЕРИСТИКА ТЕЧЕНИЯ И РЕЦИДИВА НЕОНАТАЛЬНОГО САХАРНОГО ДИАБЕТА (НСД) У ПАЦИЕНТА С ОДНОРОДИТЕЛЬСКОЙ ДИСОМИЕЙ ХРОМОСОМЫ 6Q24
}

\author{
1,2 Тихонович Ю.В., ${ }^{2,3}$ ПетряйкинаЕ.Е.
}

${ }^{1}$ ФГАОУ ВО «Первый Московский государственный медицинский университет имени И.М. Сеченова (Сеченовский Университет)» МЗ РФ, Россия, г. Москва ул. Трубецкая 8. Стр. 2

${ }^{2}$ ГБУЗ «Морозовская детская городская клиническая больница Департамента Здравоохранения г. Москвы», Россия, г. Москва 4-й Добрынинский пер., д. 1

${ }^{3}$ ФГАОУ ВО «Российский национальный исследовательский медицинский университет имени Н.И. Пирогова» МЗ РФ, Россия г. Москва ул. Островитянова д. 1 стр. 6

\section{Абстракт.}

Транзиторный неонатальный сахарный диабет (ТНСД) - редкая форма сахарного диабета (СД), манифестирующая в течение первых 6 месяцев жизни ребенка с последующим развитием клиникометаболической ремиссии. Около $2 / 3$ случаев ТНСД связано с аномалиями хромосомы 6q24, реже причиной заболевания являются мутации в генах $K C N J 11$ и $A B C C 8$. В большинстве случаев ТНСД рецидивирует в периоде пубертата. При этом у пациентов отсутствует избыток веса и повышение уровня аутоиммунных маркеров СД1 типа.

Мы описываем течение ТНСД и опыт назначения сульфанилмочевины у пациента с однородительской дисомией хромосомы 6q24.

Ключевые слова. Транзиторный неонатальный сахарный диабет, глибенкламид, 6q24ассоциированный неонатальный сахарный диабет

\section{Введение}

Неонатальный сахарный диабет (НСД) характеризуется наличием стойкой (более 2х недель) гипергликемии у детей первых 6 месяцев жизни [1,2]. Приблизительно у половины пациентов нарушения углеводного обмена носят транзиторный характер (ТНСД), что позволяет отменить инсулинотерапию в течение первых 18 месяцев жизни ребенка $[1,2,3]$

Наиболее частой причиной ТНСД являются аномалии хромосомы $6 q 24 \quad[4,5,6]$ и функциональные дефекты АТФ-чувствительных К-каналов [7].

Менее 5\% случаев приходится на ТНСД, ассоциированный с мутациями генов $H N F 1 B$, INS и ТНСД неизвестной этиологии $[8,9,10]$.

В старшем возрасте у большинства пациентов возникает рецидив заболевания. Частота рецидива составляет не менее $50 \%$ (в отдельных публикациях до 80\%). [11,12,13].

Рецидив ТНСД характеризуется нарушением первой фазы секреции инсулина без развития ожирения и повышения уровня аутоантител $[11,14]$, что клинически может напоминать течение МОДИ.

Интересно, что по данным зарубежной литературы не у всех пациентов с 6q24-ассоциированным СД в анамнезе есть указание на ТНСД, что необходимо учитывать при дифференциальной диагностике различных подтипов МОДИ, особенно при наличии низких весо-ростовых параметров при рождении [11].ๆРанее мы докладывали клинический случай ТНСД, связанный с мутацией R50Q в гене KCNJ11, с тяжелым ДКА в рецидиве заболевания [15].

В настоящей публикации мы приводим клинические характеристики ТНСД на примере пациента с однородительской дисомией хромосомы 6q24.

Клинический случай.

Пациент 13 лет поступил в отделение с жалобами на повышение гликемии после еды до 11-13 ммоль/л.

Из анамнеза известно, что ребенок от физиологической беременности, самостоятельных родов на 37 нед. Вес при рождении 1500 грамм, рост 41 см. Наследственный анамнез по эндокринной патологии 
не отягощен.

После рождения ребенок был переведен в отделение патологии новорожденных, где в возрасте 3 недель впервые было выявлено повышение гликемии до 27 ммоль/л. Установлен диагноз Неонатальный сахарный диабет (НСД), назначена инсулинотерапия актрапид, протафан по базисболюсной схеме. С 3 месяцев на фоне инсулинотерапии рецидивирующие гипогликемические состояния, с 4 месяцев - ремиссия НСД. В 2 года проведено молекулярно-генетическое исследование: мутации генов $K C N J I 1, A B C C 8$ не выявлены. В 11,5 лет при плановом обследовании отмечено повышение гликемии натощак до 7,0 ммоль/л, рекомендован контроль гликемии, ограничение углеводов с высоким гликемическим индексом.

Гликированный гемоглобин в течение года родители не определяли, вопреки рекомендациям врача. В 12,5 лет при динамическом обследовании гликемия натощак от 5,5 до 7,1 ммоль/л, после еды от 7,8 до 11 ммоль/л, низконормальные показатели базального инсулина (7,6 мкМЕ/мл) и С-пептида (1,58 нг/мл), гликированный гемоглобин 7,2\%. Заподозрен рецидив НСД, рекомендовано соблюдение диеты, динамическое наблюдение.

В 13,5 лет ребенок обследован в отделении эндокринологии УДКБ имени ИМ Сеченова. При поступлении рост 180 см (SDS 2,5), вес 63 кг (SDS ИМТ 0,49).

При обследовании: гликемия натощак 5,0-7,7 ммоль/л, через 2 часа после еды (3-4 ХЕ) 8,3-10,7 ммоль/л. Гликированный гемоглобин 8,2 \%, что свидетельствовало о хронической декомпенсации углеводного обмена, С-пептид 312 пмоль/л (298-2350), инсулин 2,1 мкМЕ/мл (2-29).

Учитывая анамнез заболевания (задержка внутриутробного развития, гипергликемия с первых недель жизни ребёнка, ремиссия НСД с 4 месяцев), заподозрен 6q24-ассоциированный НСД.

Проведен хромосомно-микроматичный анализ, выявлена однородительская дисомия 6q24.

Т.к. согласно международным исследованиям пациенты с рецидивом ТНСД могут быть успешно компенсированы на фоне назначения производных сульфонилмочевины, пациенту была проведена проба с глибенкламидом (1,75 мг) по 1/2 таблетке 2 раза в день $(0,02$ мг/кг/сутки). На этом фоне колебания гликемии в отделении от 3,9 до 7,1 ммоль/л

Гликированный гемоглобин через 3 месяца составил - 7,0\%, однако, при детальном сборе анамнеза выяснилось, что имеют место погрешности в диете и периодический пропуск приема препарата. Продолжается динамическое наблюдение и коррекция сахароснижающей терапии в амбулаторных условиях.

\section{Заключение:}

Описанный клинический случай подчеркивает необходимость регулярного контроля за состоянием углеводного обмена во время ремиссии ТНСД для своевременного распознавания рецидива заболевания и профилактики развития микрососудистых осложнений. Результаты молекулярно-генетического исследования у пациентов с НСД позволяют уточнить этиологию заболевания, назначить патогенетическую сахароснижающую терапию и определить генетические риски при дальнейшем планировании семьи. 